\title{
Delayed Thoracodorsal Artery Pseudoaneurysm After Thoracoscopic Sympathectomy for Hyperhidrosis in an Adolescent: A Case Report
}

\section{Adrian KHELIF}

ULB: Universite Libre de Bruxelles https://orcid.org/0000-0002-3417-9227

Marc LAUREYS

UVC Brugmann

Karim KHELIF ( $\square$ karim.khelif@huderf.be)

University Children's Hospital Queen Fabiola https://orcid.org/0000-0002-0934-1683

\section{Case report}

Keywords: "Thoracoscopy", "Sympathectomy", "Complication”, "Thoracodorsal artery pseudoaneurysm”, "Case Report"

Posted Date: December 9th, 2020

DOI: https://doi.org/10.21203/rs.3.rs-122899/v1

License: (a) (1) This work is licensed under a Creative Commons Attribution 4.0 International License. Read Full License 


\section{Abstract}

Background: Conversely to intercostal artery false aneurysm, thoracodorsal artery pseudoaneurysm after thoracoscopy has never been reported previously.

Case presentation: We report the case of a 15-year-old male presenting a delayed thoracodorsal artery pseudoaneurysm after bilateral thoracospic sympathectomy. Diagnosis was made by Doppler Ultrasound and confirmed by computed tomography angiography. Angiographic embolization was successfully performed.

Conclusion: Thoracodorsal artery pseudoaneurysm should be considered in patients presenting with a parietal thoracic mass following thoracoscopy. This is to the best of our knowledge the first report of thoracodorsal artery pseudoaneurysm after thoracoscopy.

\section{Background}

Primary focal hyperhidrosis, affects about $1-5 \%$ of the population. The axillae,

palms and soles are mostly involved. Although benign, it may have social, emotional and professional consequences with marked alteration of quality of life. Thoracoscopic sympathectomy (TS) is mainly offered to patients with severe and debilitating symptoms resisting to conservative management. TS has been widely advocated as a safe and efficient procedure for palmar hyperhidrosis treatment. Herein, we describe the clinical presentation and management of a delayed thoracodorsal artery pseudoaneurysm (TDAP) following bilateral TS in an adolescent.

\section{Case Report}

A 15-year-old boy with no significant medical past history presented with disabling primary focal palmar hyperhidrosis resisting to conservative treatment. Thorough disclosure of the expected results, side effects and risks related to bilateral TS were given before surgery acceptance.

Surgery was performed with the patient under general anesthesia with a standard endotracheal intubation. The patient was placed in a lateral decubitus position, and a pneumothorax achieved with a Verres needle. $\mathrm{A} 30^{\circ}$ scope was inserted through a $5-\mathrm{mm}$ trocar in the fourth intercostal space in the midaxillary line. The sympathetic trunk, including accessory nerve branches, was divided by a 3-mm diathermy hook at the level of the second, third and fourth ribs. Pneumothorax aspiration under direct vision was followed by trocar removal and drain-free skin closure.

Hemothorax and pneumothorax were ruled out with chest radiographs. The patient was discharged the next day. Hyperhidrosis was significantly improved with an uneventful postoperative course.

Three years later, the patient presented with a painful 3-cm left axillary mass. On clinical examination, the mass appeared mobile and non-pulsatile with normal overlying skin. 
Ultrasound (Fig. 1) confirmed a large-neck false aneurysm while Computed Tomography Angiography (CTA) detailed a thoracodorsal artery pseudoaneurysm (Figs. $2 \& 3$ ).

The false aneurysm was successfully excluded by means of multiple microcoils embolization, through a right endovascular femoral artery approach (Fig. 4.).

The patient left hospital on day 1 . Follow-up after 2 years remains uneventful.

Figure 1. Complex thoracic wall pseudoaneurysm on US

Figure 2 \& 3. Thoracodorsal artery pseudoaneurysm on CTA

Figure 4. Digital subtraction angiogram (DSA): TDAP exclusion by means of multiple coils embolization

\section{Discussion}

TS has proven to be highly efficient in the treatment of palmar hyperhidrosis resisting to conservative treatment. Success rate ranging from 95-98\% with lasting good long-term results have been reported ${ }^{3,4}$, 5 . Nevertheless, various complications such as pneumothoraces in $7 \%$, hemothoraces in $1 \%$, paresthesia in up to $50 \%$ and Horner's Syndrome in $1 \%$ to $2,5 \%$ were described $^{3,4}$. Moreover, compensatory hyperhidrosis appears to be the main long-term complication with an incidence of 30 to $85 \%$ 2,3,4,5.

It is noteworthy that false aneurysms have never been reported after TS, however.

Only two cases of delayed intercostal artery pseudoaneurysm after thoracoscopy were reported in the English literature. Both cases presented with a large hemothorax after intercostal artery pseudoaneurysm rupture and required surgical attention ${ }^{13,14}$. Conversely to intercostal artery pseudoaneurysm, there are no reports of TDAP after thoracoscopic surgery.

Interestingly, two non-thoracoscopic related cases of TDAP have been previously described. One resulted from fibromuscular dysplasia ${ }^{15}$ while the other occurred after latissimus dorsi free flap surgery ${ }^{16}$.

Pseudoaneurysms have a variety of causes including inflammation, infection, blunt or penetrating trauma. Surgery can result in pseudoaneurysms through direct vessel injury or the introduction of infection. In our case, we hypothesize that trocar insertion caused arterial wall continuity disruption with constitution of a blood collection between the two outer artery layers, the adventitia and the media, which over time led to symptomatic TDAP development.

In our case, TDAP presented as a painful non-pulsatile axillary lump that could have been easily confused with a variety of other soft tissue masses. Thus, exposing the patient to misdiagnosis and mismanagement. 
As an initial diagnostic modality, US picked up a pseudoaneurysm which thoracodorsal origin was detailed by CTA. Definitive diagnosis was made by DSA at the time of treatment.

In recent years, the traditional surgical management of pseudoaneurysm has been widely replaced by endovascular approaches ${ }^{17}$. Embolization by metallic coils and other materials such as hemostatic particles, glue, thrombin, polyvinyl alcohol have become generalized ${ }^{14}$. Moreover, US-guided thrombin injection in PA offers an additional interesting minimal invasive option ${ }^{17,18}$.

\section{Conclusion}

This case uniquely demonstrates the clinical and radiological features of a delayed pseudoaneurysm after thoracoscopy for sympathectomy. We herein emphasize, not only the delayed clinical presentation and the endovascular treatment of our case but most of all recognition of this unknown entity. This is to the best of our knowledge the first report of a TDPA after endoscopic TS.

\section{Abbreviations}

CTA: Computed Tomography Angiography; DSA: Digital Substraction Angiogram; TDAP: Thoracodorsal Artery Pseudoaneurysm; TS: Thorcoscopic Sympathectomy; US: Ultrasound

\section{Declarations}

\section{Acknowledgements}

We thank all clinical personnel involved in the clinical management of the patient.

\section{Funding}

None declared.

\section{Availability of data and materials}

Please contact author for data requests.

\section{Authors' contributions}

AK prepared the first draft of the manuscript and made the literature review. KK made substantial changes in the manuscript, supervised the editing process and contributed to the surgical aspects of the case. LM provided radiology pictures and contributed to manuscript revision. All authors read and approved the final manuscript.

\section{Ethics approval and consent to participate}

Not applicable. 


\section{Consent for publication}

Written consent obtained.

\section{Competing interests}

The authors declare that they have no competing interests.

\section{Author details}

${ }^{1}$ Medical Student, Université libre de Bruxelles, Brussels, Belgium.

adrian.khelif@ulb.be

${ }^{2}$ Department of Radiology,University Hospital Brugmann, ULB, Brussels, Belgium

marc.laureys@chu-brugmann.be

${ }^{3}$ Department of Surgery, University Children's Hospital Queen Fabiola, ULB, Brussels, Belgium.

karim.khelif@huderf.be

\section{References}

1. Smith Christopher C, Pariser D. Primary focal hyperhidrosis https://www.uptodate.com/contents/primary-focal-hyperhidrosis, Accessed 20 October 2020.

2. Fibla JJ, Molins L, Mier JM, Vidal G. Effectiveness of sympathetic block by clipping in the treatment of hyperhidrosis and facial blushing. Interact Cardiovasc Thorac Surg déc. 2009;9(6):9702.

3. Moraites E, Vaughn OA, Hill S. Endoscopic thoracic sympathectomy. Dermatol Clin oct. 2014;32(4):5418.

4. Herbst F, Plas EG, Függer R, Fritsch A. Endoscopic thoracic sympathectomy for primary hyperhidrosis of the upper limbs. A critical analysis and long-term results of 480 operations. Ann Surg juill. 1994;220(1):8690.

5. Atkinson JLD, Fode-Thomas NC, Fealey RD, Eisenach JH, Goerss SJ. Endoscopic transthoracic limited sympathotomy for palmar-plantar hyperhidrosis: outcomes and complications during a 10year period. Mayo Clin Proc. août 2011;86(8):7219.

6. Drott C, Göthberg G, Claes G. Endoscopic transthoracic sympathectomy: an efficient and safe method for the treatment of hyperhidrosis. J Am Acad Dermatol juill. 1995;33(1):7881.

7. Neumayer C, Zacherl J, Holak G, et al. Limited endoscopic thoracic sympathetic block for hyperhidrosis of the upper limb: reduction of compensatory sweating by clipping T4. Surg Endosc janv. 2004;18(1):1526. 
8. Gossot D, Galetta D, Pascal A, et al. Long-term results of endoscopic thoracic sympathectomy for upper limb hyperhidrosis. Ann Thorac Surg avr. 2003;75(4):10759.

9. Dumont $P$, Denoyer A, Robin P. Long-term results of thoracoscopic sympathectomy for hyperhidrosis. Ann Thorac Surg nov. 2004;78(5):18017.

10. Hornberger J, Grimes K, Naumann M, et al. Recognition, diagnosis, and treatment of primary focal hyperhidrosis. J Am Acad Dermatol août. 2004;51(2):27486.

11. Licht PB, Pilegaard HK. Severity of compensatory sweating after thoracoscopic sympathectomy. Ann Thorac Surg août. 2004;78(2):42731.

12. Brantley S, Spies J. Thoracodorsal artery aneurysm caused by fibromuscular dysplasia. American Journal of Roentgenology nov. 1987;149(5):10678.

13. Atherton WG, Morgan WE. False aneurysm of an intercostal artery after thoracoscopic sympathectomy. Ann R Coll Surg Engl mai. 1997;79(3):22930.

14. Rossi G, Perrillo M, Flora $M$, et al. Incidental diagnosis and therapeutic approach of an iatrogenic intra-parenchymal pulmonary intercostal artery pseudoaneurysm: a case report. Monaldi Arch Chest Dis. 30 août 2019;89(3).

15. Brantley SD, Spies JB. Thoracodorsal artery aneurysm caused by fibromuscular dysplasia. AJR Am J Roentgenol. 1987 Nov;149(5):1067-8.

16. Ceulemans P, Van Landuyt K, Hamdi M, Blondeel P, Matton G, Monstrey S. Complete survival of a free flap after early pseudoaneurysm formation and pedicle thrombosis. Ann Plast Surg. 2001 Sep;47(3):332-5.

17. Yamakado K, Nakatsuka A, Tanaka N, Takano K, Matsumura K, Takeda K. Transcatheter arterial embolization of ruptured pseudoaneurysms with coils and n-butyl cyanoacrylate. J Vasc Interv Radiol. 2000 Jan;11(1):66-72.

18. Sekino S, Takagi H, Kubota H, Kato T, Matsuno Y, Umemoto T. Intercostal artery pseudoaneurysm due to stab wound. J Vasc Surg. 2005 Aug;42(2):352-6.

\section{Figures}




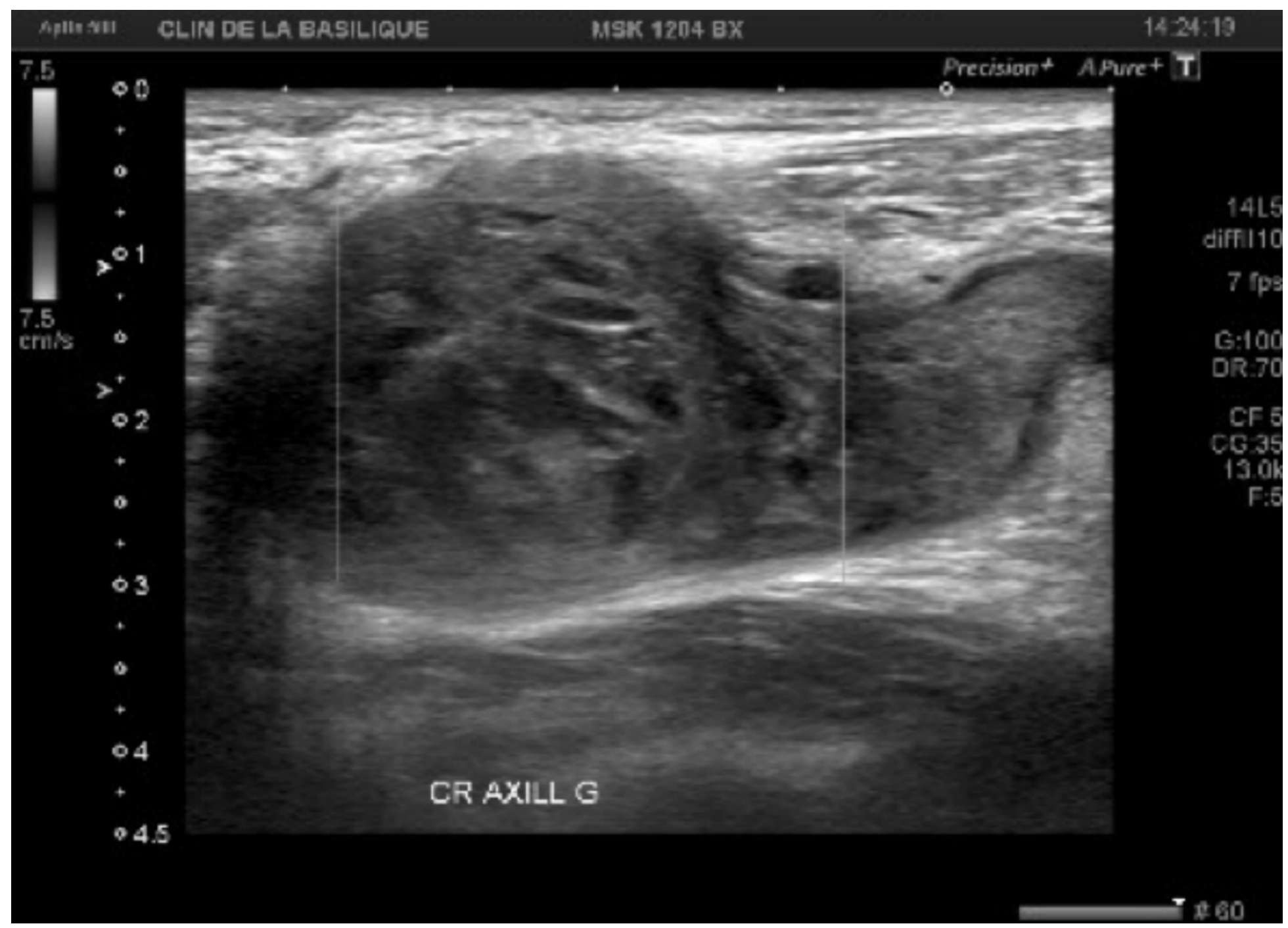

Figure 1

Complex thoracic wall pseudoaneurysm on US 


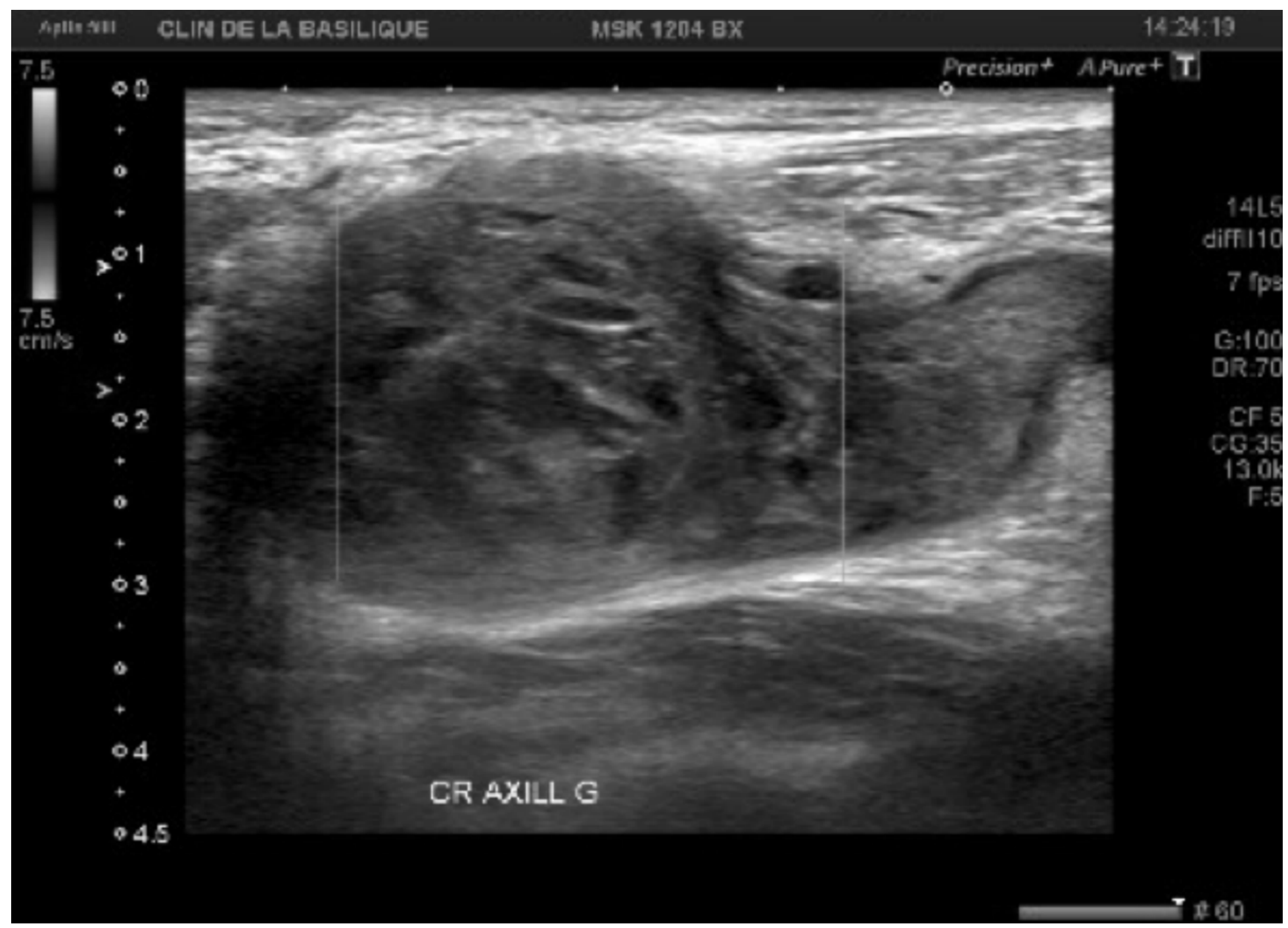

Figure 1

Complex thoracic wall pseudoaneurysm on US 


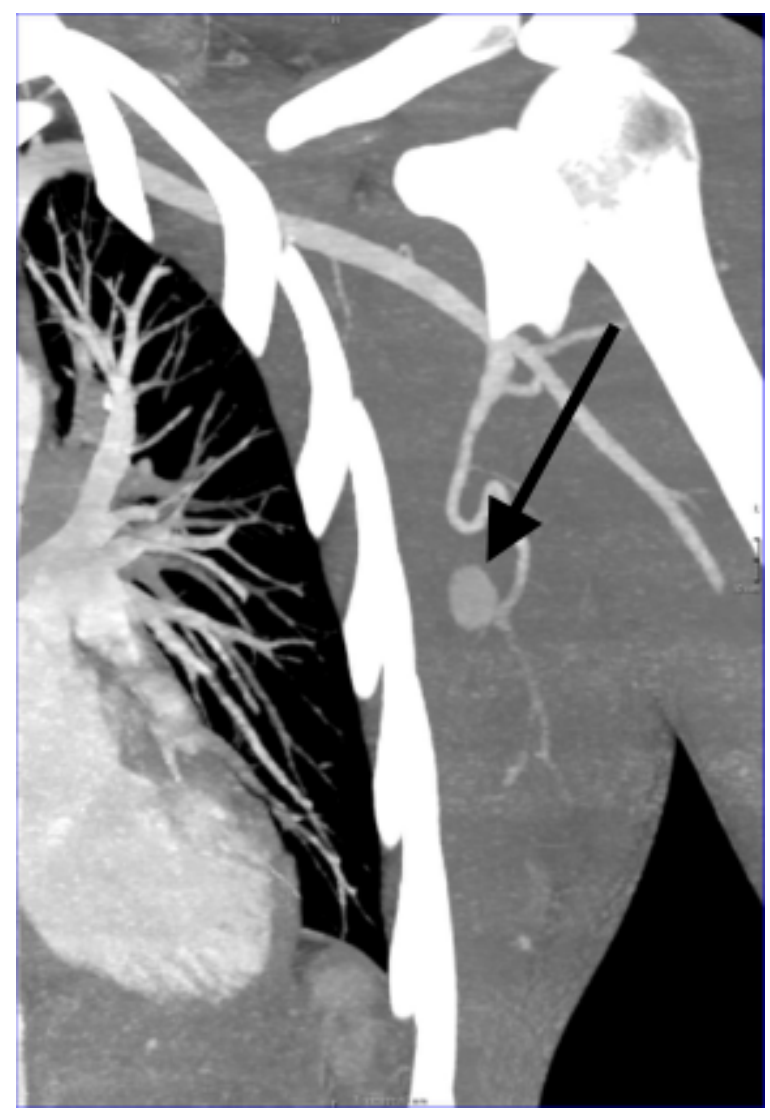

Figure 2

Thoracodorsal artery pseudoaneurysm on CTA

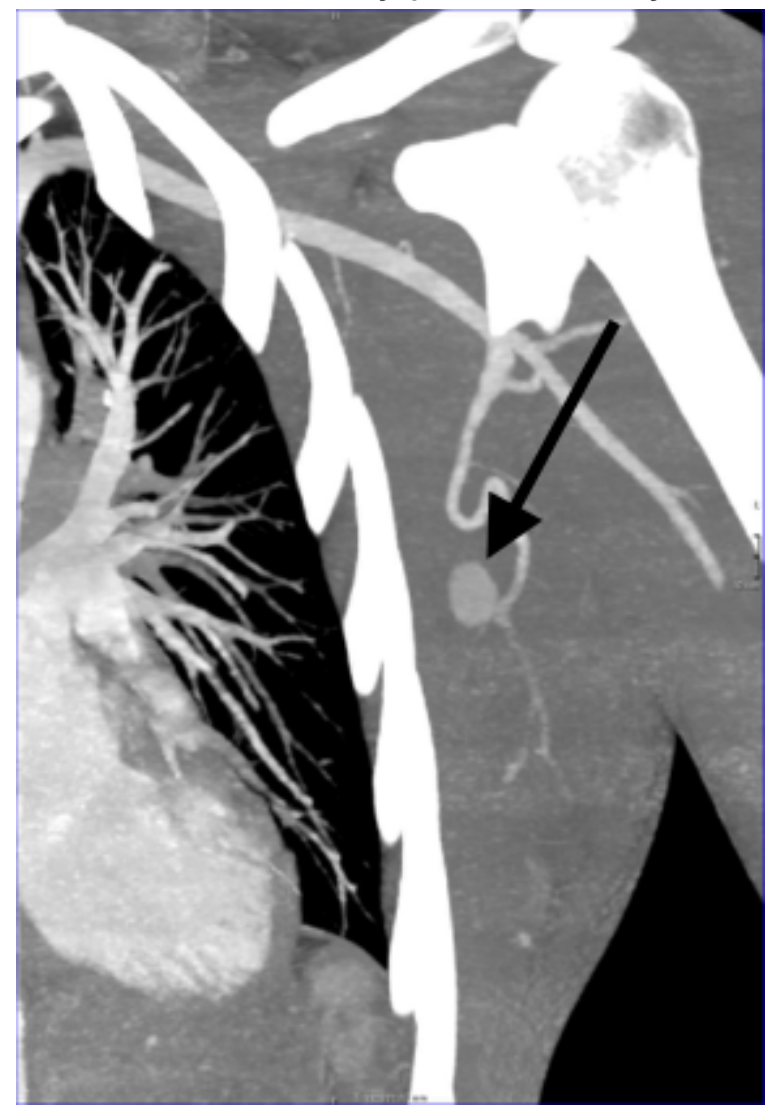


Figure 2

Thoracodorsal artery pseudoaneurysm on CTA

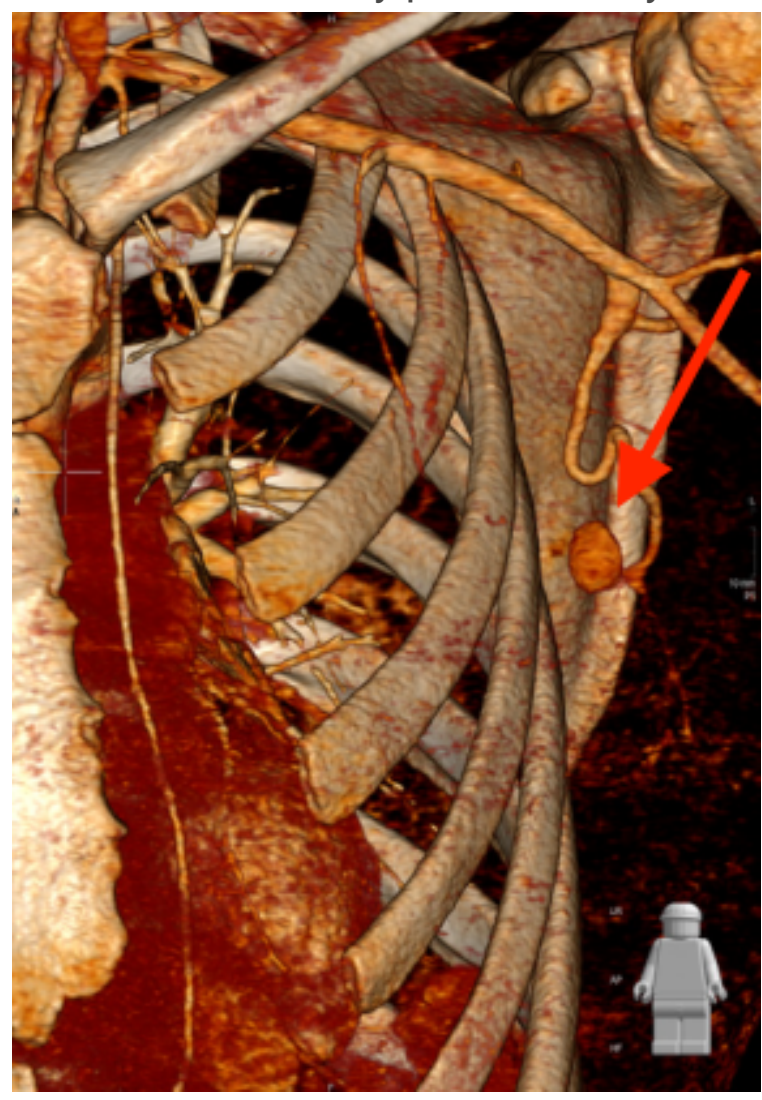

Figure 3

Thoracodorsal artery pseudoaneurysm on CTA 


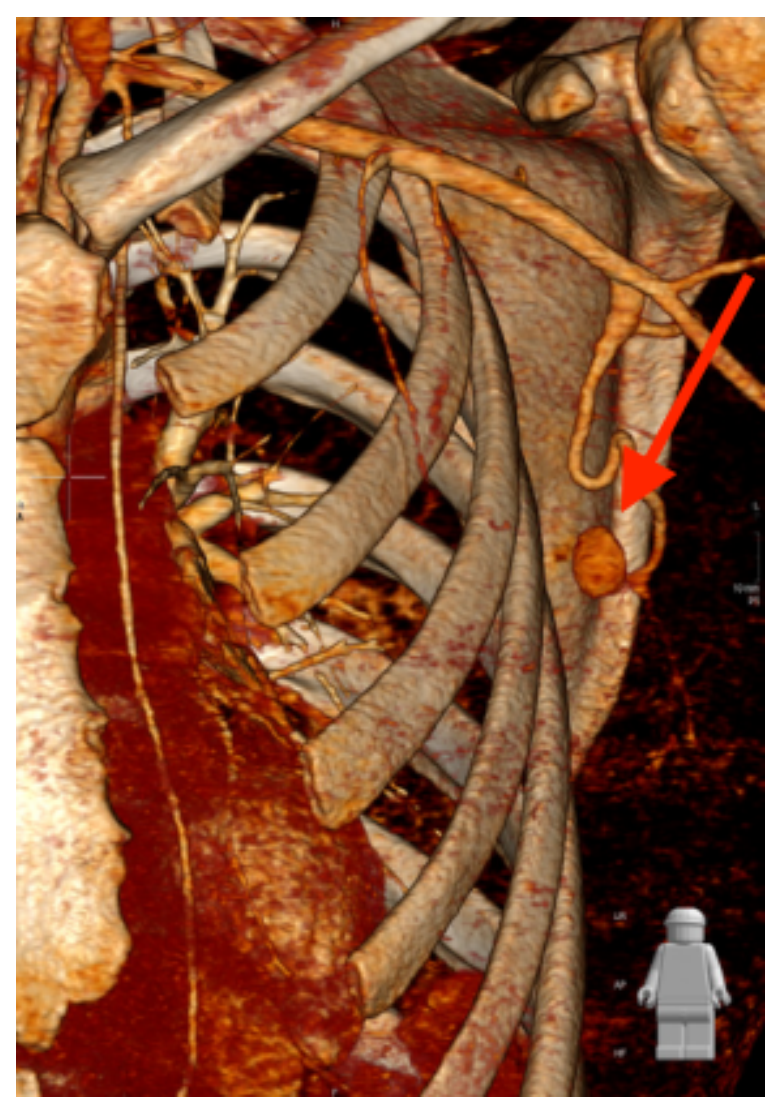

Figure 3

Thoracodorsal artery pseudoaneurysm on CTA 


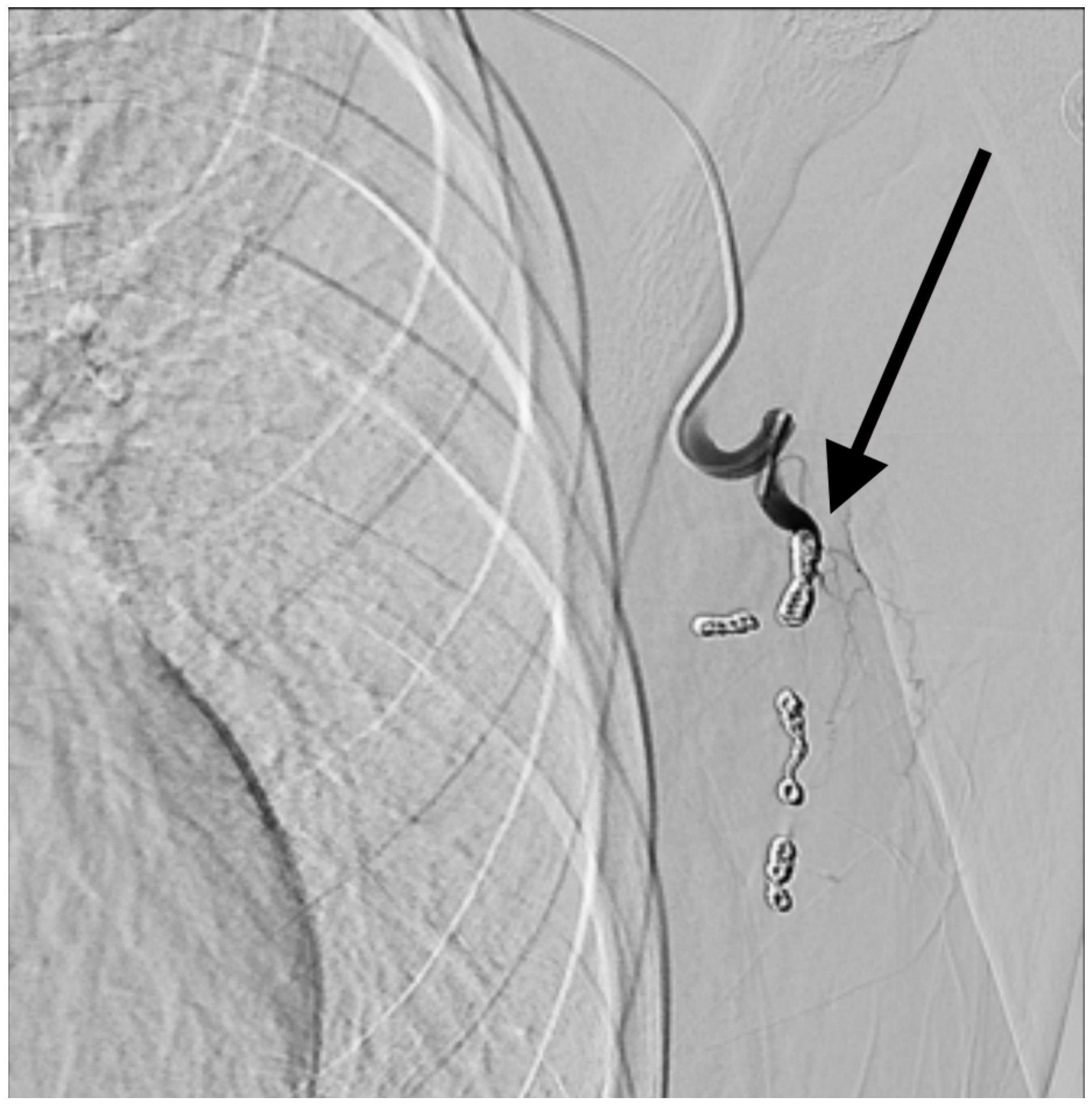

Figure 4

Digital subtraction angiogram (DSA): TDAP exclusion by means of multiple coils embolization 


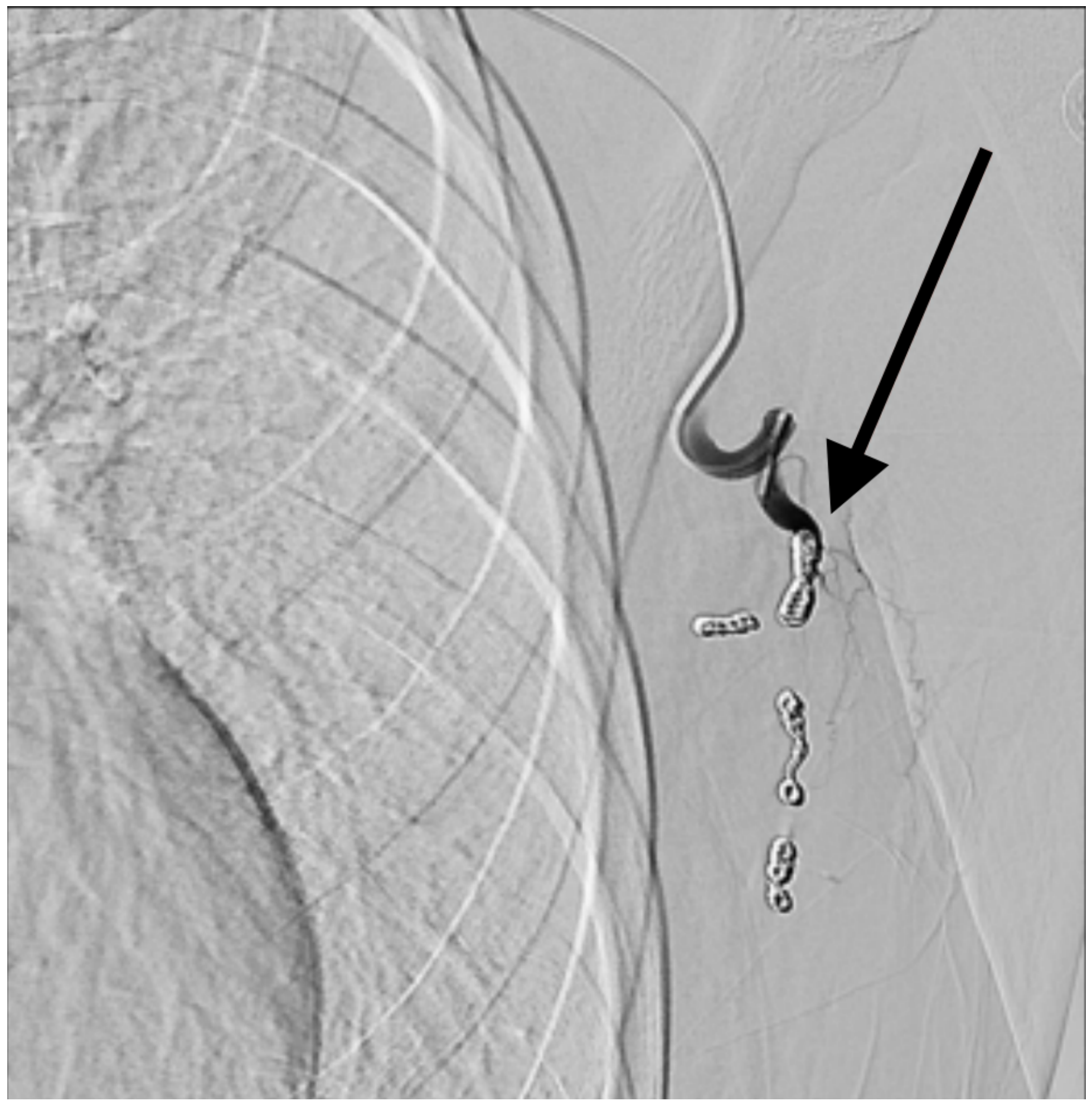

\section{Figure 4}

Digital subtraction angiogram (DSA): TDAP exclusion by means of multiple coils embolization

\section{Supplementary Files}

This is a list of supplementary files associated with this preprint. Click to download. 
- CAREchecklistTDAP.pdf

- CAREchecklistTDAP.pdf 